\title{
Representation of women on the editorial board of the Canadian Journal of Anesthesia: a retrospective analysis from 1954 to 2018
}

\author{
Gianni R. Lorello, BSc, MD, MSc (Med Ed), CIP, FRCPC (1) • Arun Parmar, BHSc(c) • \\ Alana M. Flexman, MD, FRCPC
}

Received: 13 April 2019/Revised: 15 April 2019/Accepted: 15 April 2019/Published online: 29 April 2019

(C) Canadian Anesthesiologists' Society 2019

\section{To the Editor,}

Editorial board membership is prestigious in academic medicine. The National Academy of Sciences and Institute of Medicine has called for "reasonable representation of women on editorial boards and in other...leadership positions." ${ }^{1}$ Although women represent an increasing proportion of anesthesiologists in Canada, ${ }^{2}$ women remain poorly represented in senior leadership positions. ${ }^{3}$ We compared the proportion of women on the Canadian Journal of Anesthesia (CJA) editorial board with the proportion of women anesthesiologists in Canada over time.

We conducted a retrospective analysis of the gender of the CJA editorial board members since inception (1954) to

Electronic supplementary material The online version of this article (https://doi.org/10.1007/s12630-019-01378-9) contains supplementary material, which is available to authorized users.

G. R. Lorello, BSc, MD, MSc (Med Ed), CIP, FRCPC ( $₫)$ Department of Anesthesiology and Pain Medicine, University Health Network, Toronto, ON, Canada

e-mail: Gianni.Lorello@uhn.ca

Department of Anesthesia, The University of Toronto, Toronto, ON, Canada

The Wilson Centre, Toronto, ON, Canada

A. Parmar, BHSc(c)

Department of Anesthesiology and Pain Medicine, University Health Network, Toronto, ON, Canada

\section{A. M. Flexman, MD, FRCPC \\ Department of Anesthesiology, Vancouver General Hospital, Vancouver, BC, Canada}

Department of Anesthesiology and Perioperative Care, The University of British Columbia, Vancouver, BC, Canada
2018. Ethical approval was not required as we included publicly available data. We assigned gender as previously described. ${ }^{4}$ Editorial board membership was determined by reviewing the journal mastheads of each year. We included the editor-in-chief, deputy editor-in-chief, associate editor(s), statistical editor(s), French language editor, continuing professional development editor, board members, and guest editors. We assigned a "memberposition" to each person on the board in each year. The concurrent proportion of women anesthesiologists in Canada was determined from Canadian Medical Association data.

We identified the editorial board in all years except 1983 and 1992 (editorial board not listed), and 2000 (print copy missing). We identified 985 member positions (i.e., members multiplied by the length of their corresponding term in years) and assigned a gender to all but 26 member positions (four individuals), leaving 959 member positions for analysis.

A total of 146 people made up 985 member positions of the CJA editorial board: $10 \%$ were (14/145) women and $88 \%$ (127/145) were men. Women comprised 6\% (58/959) of member positions since 1954 (eTable, available as Electronic Supplementary Material). Members spent a median [interquartile range] of 6 [4-9] years on the editorial board, with men spending more time than women (7 [4-9] vs 3 [2-6] years). Since the first woman joined the board in 1996, women accounted for $11 \%(58 / 517)$ of member positions, ranging from a low of $0 \%(0 / 27)$ in 2014 to a high of 19\% (5/27) in 2017 (Figure). Women made up $2 \%$ (1/58) of deputy/associate editor positions and 6\% (6/ 108) of international member positions. The proportion of practicing anesthesiologists in Canada that were women increased from $20 \%$ in 1994 to $33 \%$ in 2018. The percentage of women anesthesiologists in Canada and 


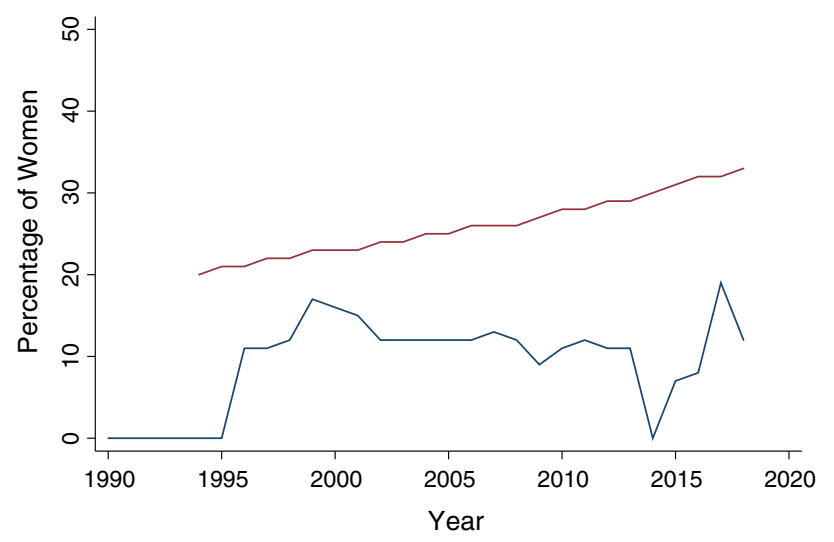

CJA Editorial Board —— Anesthesiologists in Canada

Figure Proportion of women editorial board members over time. The red line depicts the proportion of women anesthesiologists in Canada since 1994 (provided by the Canadian Medical Association). Data were not included in the figure prior to 1990 because no women were on the Canadian Journal of Anesthesia editorial board prior to 1996

women editorial board members were not correlated (Spearman rho, -0.0203; $P=0.93$ ).

Despite an increasing number of women in anesthesiology in Canada, our data show that women remain underrepresented on the CJA editorial board, a finding not unique to the CJA and consistent with other journals. In 2011, $15 \%$ of women constituted the editorial board of five major anesthesia-related journals, ranging from 7\% (Anesthesia and Analgesia) to 24\% (European Journal of Pain). ${ }^{5}$

The underrepresentation of women in our study may reflect a lower level of women participating in academic anesthesiology. ${ }^{4}$ Nevertheless, women have authored 25 $29 \%$ of original articles in the CJA in recent decades, ${ }^{4}$ similar to the proportion of women anesthesiologists in Canada. Women make up a relatively lower proportion of older anesthesiologists, ${ }^{2}$ which may partially account for our findings. Determining the optimal proportion of women on editorial boards is difficult, ${ }^{5}$ and editorial boards must balance all axes of diversity, including, but not limited to, gender, region, ethnicity, language, and sexual orientation. One should not come at the expense of another.
Limitations of this study include our inability to determine the proportion of women invited to the board $v s$ the proportion of those invited who declined, and the proportion of women active in academic medicine. The proportion of women practicing anesthesiology is limited by sampling techniques.

Although not included in our data, we note that the 2019 CJA editorial board has encouragingly increased to $25 \%$ women. The reasons behind this pervasive underrepresentation are multifactorial and further examination is urgently required to identify strategies to increase the participation of women on editorial boards.

Acknowledgement We gratefully acknowledge the Canadian Anesthesiologists' Society and Ms. Debra Thompson for providing access to the full print collection of the Canadian Journal of Anesthesia.

Conflicts of interest None declared.

Editorial responsibility This submission was handled by Dr. Hilary P. Grocott, Editor-in-Chief, Canadian Journal of Anesthesia.

\section{References}

1. National Academy of Sciences, National Academy of Engineering, Institute of Medicine. Beyond Bias and Barriers. Washington, D.C.: The National Academies Press; 2007.

2. Mottiar M. Because it's 2018: women in Canadian anesthesiology. Can J Anesth 2018; 65: 953-4.

3. Lorello GR, Flexman AM. 75 years of leadership in the Canadian Anesthesiologists' Society: a gender analysis. Can J Anesth 2019; DOI: 10.1007/s12630-019-01359-y.

4. Flexman AM, Parmar A, Lorello GR. Representation of female authors in the Canadian Journal of Anesthesia: a retrospective analysis of articles between 1954 and 2017. Can J Anesth 2019; 66: 495-502.

5. Amrein K, Langmann A, Fahrleitner-Pammer A, Pieber TR, Zollner-Schwetz I. Women underrepresented on editorial boards of 60 major medical journals. Gender Med 2011; 8: 378-87.

Publisher's Note Springer Nature remains neutral with regard to jurisdictional claims in published maps and institutional affiliations. 